\title{
Can disease activity in patients with psoriatic arthritis be adequately assessed by a modified disease activity index for psoriatic arthritis (DAPSA) based on 28 joints?
}

Brigitte Michelsen ${ }^{1,2}$, Joseph Sexton ${ }^{1}$, Josef S Smolen ${ }^{3}$, Daniel Aletaha ${ }^{3}$, Niels Steen Krogh ${ }^{4}$, Désirée van der Heijde ${ }^{1,5}$, Tore K Kvien ${ }^{1}$, Merete Lund Hetland ${ }^{6,7}$

${ }^{1}$ Department of Rheumatology, Diakonhjemmet Hospital, Oslo, Norway; ${ }^{2}$ Division of Rheumatology, Department of Medicine, Hospital of Southern Norway Trust, Kristiansand, Norway; ${ }^{3}$ Division of Rheumatology, Department of Internal Medicine III, Medical University of Vienna and Lainz Hospital, Vienna, Austria; ${ }^{4}$ ZiteLab ApS, Frederiksberg, Denmark; ${ }^{5}$ Department of Rheumatology, Leiden University Medical Center, Leiden, The Netherlands; ${ }^{6}$ DANBIO, Copenhagen Center for Arthritis Research (COPECARE), Center for Rheumatology and Spine Diseases, Centre of Head and Orthopaedics, Rigshospitalet, Copenhagen, Denmark; ${ }^{7}$ Department of Clinical Medicine, Faculty of Health and Medical Sciences, University of Copenhagen, Copenhagen, Denmark.

Correspondence to: Brigitte Michelsen, Department of Rheumatology, Diakonhjemmet Hospital, Box 23 Vinderen, Oslo, Norway; brigitte_michelsen@yahoo.no

Word count: 2095 


\section{ABSTRACT}

\section{Objective}

To test the psychometric performance of a modified Disease Activity index for PSoriatic Arthritis (DAPSA) using 28 instead of 66 swollen/68 tender joint counts (SJC/TJC).

\section{Methods}

We included PsA patients from the Danish national quality registry DANBIO, divided into examination ( $n=3157$ patients, 23987 visits) and validation cohorts ( $n=3154$ patients, 24160

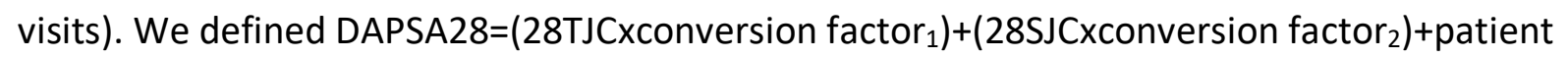
global[0-10VAS]+pain[0-10VAS]+CRP[mg/dL]. Identification of the conversion factors was performed by Generalized Estimating Equations in the examination cohort and evaluation of criterion, correlational and construct validity in the validation cohort.

\section{Results}

We estimated DAPSA28=(28TJCx1.6)+(28SJCx1.6)+patient global[0-10VAS]+pain[010VAS]+CRP[mg/dL]. Criterion validity: DAPSA/DAPSA28 had comparable discriminative power expressed as standardized mean difference (DAPSA, 0.90; DAPSA28, 0.93) to distinguish between patients in high and low disease activity. Kappa with quadratic weighting of DAPSA/DAPSA28 disease activity states was high; $0.9295 \% \mathrm{Cl}$ (0.92-0.92). Standardized response means for DAPSA/DAPSA28 were $-0.96 /-0.92$ for visits after bDMARD-initiation. Correlational validity: Baseline DAPSA/DAPSA28 had high correlation with DAS28CRP ( $r=0.87 / r=0.93)$, SDAI $(r=0.92 / r=0.99), p<0.001$. Bland-Altman plot showed better agreement between DAPSA/DAPSA28 for low than high disease activity. Construct validity: DAPSA/DAPSA28 were similarly correlated to $H A Q ; r=0.60 / 0.62, p<0.001$.

DAPSA/DAPSA28 discriminated patients reporting their symptom state as acceptable vs. not acceptable equally well: mean(SD) 9.1(8.7)/8.4(8.0) and 24.2(14.9)/22.5(13.8), respectively.

\section{Conclusion}

Our study suggests that data sets with only 28-joint counts available can be used to calculate DAPSA28, especially in patients with low disease activity. DAPSA28 showed good criterion, correlational and construct validity, and sensitivity to change. Still, our results support that $66 / 68$ joint count should be performed and the original DAPSA should be preferred in PsA. 


\section{BACKGROUND}

The Disease Activity index for PSoriatic Arthritis (DAPSA), originally developed for reactive arthritis, ${ }^{1}$ was validated for psoriatic arthritis (PsA) in 2010 and is based on the simple summation of visual analogue scales $(0-10 \mathrm{~cm})$ of patient's global and pain assessments, 66 swollen joint count (66SJC), 68 tender joint count (68TJC) and C-reactive protein (CRP, $\mathrm{mg} / \mathrm{dL}$ ). ${ }^{2}$ These variables had previously been identified in principal component analysis as most reflective of PsA disease activity. ${ }^{3}$

In 2015 cut-off values for DAPSA remission ( $\leq 4)$, low ( $\leq 14)$, moderate $(>14 \leq 28)$ and high (>28) disease activity were proposed, as well as debated. ${ }^{4-6}$

By virtue of joint involvement in PsA, which often comprises swelling and tenderness of distal interphalangeal, ankle and foot joints, the 66/68 joint counts are traditionally used to assess PsA patients during clinical examinations. However, many databases and registries solely collect 28 joint counts and not the comprehensive 66/68 joint counts, not only in RA but also in PsA patients, despite the lack of face validity of reduced joint counts outside of RA. In the present study we assessed whether reduced joint counts may be utilised post-hoc also for PsA, or if they have to be regarded as insufficient and thus "lost" for that purpose. The background for this study was also that 28 -joint counts have been found to be sufficiently valid in comparison to more comprehensive joint counts in patients with RA. ${ }^{7-9}$ Thus, the objective of this study was to compute and test the potential validity of a simplified DAPSA score including 28 instead of the original 66/68 joint counts in PsA patients from the Danish national quality registry DANBIO.

\section{METHODS}

\section{DANBIO}

DANBIO is a Danish national quality registry established in year 2000 which provides data on the disease course of patients with RA, PsA and ankylosing spondylitis, regardless of treatment. ${ }^{10}$ From year 2006 registration of patients treated with biologic DMARDs (bDMARDs) has been mandatory. The completeness of DANBIO regarding the overall use of bDMARDs in Denmark has been estimated to be $\geq 92 \% .{ }^{10}$ PsA patients with peripheral disease are routinely monitored by 28 -joint disease activity score (DAS28; 4 variables, CRP). The 66/68 joint counts are optional. Information on subgroups of PSA (e.g. oligoarthritis, polyarthritis, arthritis mutilans) is not recorded. Fully anonymized DANBIO data on patients with ICD-10 code 07.03A (Psoriatic Arthritis) were collected. The study was approved by the DANBIO steering committee, the RKKP (Regionernes Kliniske Kvalitetsudviklingsprogram) as well as the data authorities. Patients' informed consent and research ethical approval are not necessary for this kind of study according to Danish law.

\section{Statistical analyses}

Statistical analyses were performed according to a predefined statistical analysis plan. 
Descriptive statistics were used to summarize patients' demographic and baseline variables. Quantitative results were compared using Mann-Whitney $U$ test or independent $t$-test as appropriate and proportions using Chi-Square test. The cohort was divided into one examination and one validation cohort according to odd or even ID numbers.

We defined: DAPSA28 $=\left(28 \mathrm{TJC} \mathrm{x}\right.$ conversion factor $\left._{1}\right)+\left(28 \mathrm{SJC} \times\right.$ conversion factor $\left._{2}\right)+$ patient's global assessment [0-10 VAS] + patient's pain assessment [0-10 VAS] + CRP $[\mathrm{mg} / \mathrm{dL}]$. Identification of the conversion factors was performed by Generalized Estimating Equations (GEE, multiple visits per patient) with 68TJC/66SJC as dependent and 28TJC/28SJC as independent variables in the examination cohort. All further analyses were performed in the validation cohort.

Evaluation of criterion validity was performed through 1) assessment of Pearson correlation between physician's global assessment and DAPSA/DAPSA28, 2) evaluation of the discriminative power of DAPSA/DAPSA28 to distinguish between groups with high (defined as starting bDMARD treatment) or low (defined as not starting or changing synthetic/biologic DMARD (s/bDMARD) treatment for $\geq 60$ days) disease activity, including assessment of standardized mean differences (mean differences divided by pooled SD), 3) Agreement between DAPSA/DAPSA28 disease activity categories, including kappa coefficients with linear and quadratic weighting, 4) standardized response means (SRMs).

Evaluation of correlational validity was performed through 1) correlations between changes from start of s/bDMARD treatment to follow-up visits in 28SJC and 66SJC, and in 28TJC and $68 T J C, 2)$ scatterplots to visualize correlations between DAPSA and DAPSA28, 3) correlations between simplified disease activity index (SDAI), clinical disease activity index (CDAI), DAS28CRP and DAPSA/DAPSA28, 4) Bland-Altman plot ${ }^{11}$ of DAPSA and DAPSA28.

Evaluation of construct validity was performed through 1) Comparison of mean (SD) DAPSA/DAPSA28 according to the change and state scores/external anchors: a) patient's evaluation of disease activity (much worse, worse, little worse, unchanged, little better, better or much better), b) patient's acceptable symptom state and c) physician's global assessment with a cut-off $<10$ (0-100 scale), 2) correlations of DAPSA/DAPSA28 with HAQ at several points in time and comparison of mean (SD) HAQ levels for patients in different DAPSA/DAPSA28 disease activity states.

We defined the strength of Pearson correlation coefficients as; none: $<0.2$, low: 0.2-0.3, moderate: $>0.3-<0.5$, substantial: $0.5-0.7$ and high: $>0.7$. Statistical tests were performed using SPSS for Windows V.23.0.

\section{RESULTS}

Demographics and baseline disease activity measures were similar in the examination and validation cohorts (table 1). 
Table 1 Demographic characteristics and baseline variables

\begin{tabular}{|c|c|c|c|}
\hline & $\begin{array}{l}\text { Examination cohort } \\
\text { ( } n=3157 \text { with } \\
23987 \text { visits) }\end{array}$ & $\begin{array}{l}\text { Validation cohort } \\
\text { ( } n=3154 \text { with } \\
24160 \text { visits) }\end{array}$ & $p$-value \\
\hline Age (years), mean (SD) & $52.0(13.8)$ & $52.0(13.8)$ & 0.96 \\
\hline Female, n (\%) & $1746(55.3)$ & $1686(53.5)$ & 0.14 \\
\hline $\begin{array}{l}66 \text { swollen joint count, mean } \\
\text { (SD)/ median }\left(25^{\text {th }}, 75^{\text {th }}\right. \\
\text { percentile) }\end{array}$ & $\begin{array}{l}2.3(4.1) / 0(0,3) \\
(n=1449)\end{array}$ & $\begin{array}{l}2.4(4.4) / 0(0,3) \\
(n=1450)\end{array}$ & 0.55 \\
\hline $\begin{array}{l}28 \text { swollen joint count, mean } \\
\text { (SD)/ median }\left(25^{\text {th }}, 75^{\text {th }}\right. \\
\text { percentile) }\end{array}$ & $\begin{array}{l}1.3(2.5) / 0(0,2) \\
(n=3157)\end{array}$ & $\begin{array}{l}1.3(2.4) / 0(0,2) \\
(n=3154)\end{array}$ & 0.53 \\
\hline $\begin{array}{l}68 \text { tender joint count, mean } \\
\text { (SD)/ median }\left(25^{\text {th }}, 75^{\text {th }}\right. \\
\text { percentile) }\end{array}$ & $\begin{array}{l}6.7(9.2) / 3(0,9) \\
(n=1510)\end{array}$ & $\begin{array}{l}6.8(9.3) / 4(0,9) \\
(n=1506)\end{array}$ & 0.42 \\
\hline $\begin{array}{l}28 \text { tender joint count, mean } \\
\text { (SD)/ median }\left(25^{\text {th }}, 75^{\text {th }}\right. \\
\text { percentile) }\end{array}$ & $\begin{array}{l}3.4(5.2) / 1(0,5) \\
(n=3157)\end{array}$ & $\begin{array}{l}3.3(5.0) / 1(0,4) \\
(n=3154)\end{array}$ & 0.45 \\
\hline $\begin{array}{l}\text { Patient's global, } 0-100 \text { VAS } \\
\text { scale, mean (SD)/ median } \\
\left(25^{\text {th }}, 75^{\text {th }} \text { percentile }\right)\end{array}$ & $\begin{array}{l}46.4(29.6) / 48(20,71) \\
(n=2732)\end{array}$ & $\begin{array}{l}45.9(29.0) / 46(20,70) \\
(n=2728)\end{array}$ & 0.53 \\
\hline $\begin{array}{l}\text { Evaluator's global, } 0-100 \text { VAS } \\
\text { scale, mean (SD)/ median } \\
\left(25^{\text {th }}, 75^{\text {th }} \text { percentile }\right)\end{array}$ & $\begin{array}{l}16.7(15.8) / 12(5,24) \\
(n=2792)\end{array}$ & $\begin{array}{l}16.8(15.6) / 12(5,24) \\
(n=2806)\end{array}$ & 0.83 \\
\hline $\begin{array}{l}\text { Patient's pain, } 0-100 \text { VAS } \\
\text { scale, mean (SD)/ median } \\
\left(25^{\text {th }}, 75^{\text {th }} \text { percentile }\right)\end{array}$ & $\begin{array}{l}41.0(26.9) / 38(19,63) \\
(n=2664)\end{array}$ & $\begin{array}{l}40.3(26.4) / 37(18,61) \\
(n=2670)\end{array}$ & 0.68 \\
\hline $\begin{array}{l}\mathrm{CRP}, \mathrm{mg} / \mathrm{L}, \text { mean }(\mathrm{SD}) / \\
\text { median }\left(25^{\text {th }}, 75^{\text {th }} \text { percentile }\right)\end{array}$ & $\begin{array}{l}8.6(16.0) / 4(2,9) \\
(n=2780)\end{array}$ & $\begin{array}{l}8.4(13.0) / 4(2,10) \\
(n=2754)\end{array}$ & 0.73 \\
\hline $\begin{array}{l}\text { SDAI, mean (SD)/ median } \\
\left(25^{\text {th }}, 75^{\text {th }} \text { percentile }\right)\end{array}$ & $\begin{array}{l}11.9(9.9) / 9.4(4.5 \\
16.3)(n=2200)\end{array}$ & $\begin{array}{l}11.5(9.7) / 9(2,16) \\
(n=2189)\end{array}$ & 0.22 \\
\hline $\begin{array}{l}\text { CDAl, mean (SD) } / \text { median } \\
\left(25^{\text {th }}, 75^{\text {th }} \text { percentile }\right)\end{array}$ & $\begin{array}{l}11.0(9.5) / 8.7(4.0, \\
15.3)(n=2427)\end{array}$ & $\begin{array}{l}10.7(9.2) / 8.3(4.0, \\
14.9)(n=2436)\end{array}$ & 0.33 \\
\hline $\begin{array}{l}\text { DAS28CRP, mean (SD)/ } \\
\text { median }\left(25^{\text {th }}, 75^{\text {th }} \text { percentile }\right)\end{array}$ & $\begin{array}{l}3.1(1.3) / 3.0(2.1,4.0) \\
(n=2483)\end{array}$ & $\begin{array}{l}3.1(1.3) / 2.9(2.1,4.0) \\
(n=2455)\end{array}$ & 0.16 \\
\hline $\begin{array}{l}\text { HAQ, mean (SD)/ median } \\
\left(25^{\text {th }}, 75^{\text {th }} \text { percentile }\right)\end{array}$ & $\begin{array}{l}0.7(0.6) / 0.6(0.1,1.1) \\
(n=2610)\end{array}$ & $\begin{array}{l}0.7(0.6) / 0.6(0.1,1.0) \\
(n=2593)\end{array}$ & 0.30 \\
\hline
\end{tabular}

CDAI, clinical disease activity index; CRP, C-reactive protein; DAS28CRP, 28-joint disease activity score with CRP; HAQ, Health Assessment Questionnaire; SDAl, simplified disease activity index 


\section{Transformation to DAPSA28}

By means of GEE we estimated a conversion factor of 1.6 for both TJC $95 \% \mathrm{Cl}$ (1.6-1.7) [8179 visits included] and for SJC 95\% Cl (1.5-1.6) [7701 visits included], leading to:

DAPSA28 $=(28 \mathrm{TJC} \times 1.6)+(28 \mathrm{SJC} \times 1.6)+$ patient's global assessment $[0-10 \mathrm{VAS}]+$ patient's pain assessment [0-10 VAS] + CRP $[\mathrm{mg} / \mathrm{dL}]$

DAPSA and DAPSA28 scores were similar in the examination ( $n=1949$ patients with 5995 visits) vs. validation cohorts (1975 patients with 6421 visits); Mean (SD)/median (25th-75th percentiles) DAPSA: 16.4 (14.5)/12.9 (5.6-22.9) vs. 16.4 (14.5)/13.0 (5.8-22.2), $p=0.90$; DAPSA28: 14.9 (13.7)/11.5 (5.1-20.2) vs. 14.9 (13.3)/11.7 (5.2-20.0), $p=0.99$, respectively. All further analyses were performed in the validation cohort.

Boxplot showed similar medians $\left(25^{\text {th }}-75^{\text {th }}\right.$ percentiles), but some more extreme values for DAPSA (supplementary figure S1).

\section{Criterion validity}

Physician's global assessment and DAPSA/DAPSA28 were overall substantially and similarly correlated $(r=0.63 / r=0.61), p<0.001$.

DAPSA and DAPSA28 had comparable discriminative power, expressed as standardized mean difference, to distinguish between patients in high and low disease activity (table 2).

Table 2 Discriminative power to distinguish between patients in high and low disease activity

\begin{tabular}{|l|l|l|c|}
\hline & $\begin{array}{l}\text { Patients starting } \\
\text { bDMARD } \\
\text { treatment }\end{array}$ & $\begin{array}{l}\text { Patients not starting or } \\
\text { changing s/bDMARD } \\
\text { treatment for } \mathbf{6 0} \text { days }\end{array}$ & $\begin{array}{c}\text { Standardized } \\
\text { mean } \\
\text { difference* }\end{array}$ \\
\hline Number of visits/ patients & $391 / 290$ & $1946 / 774$ & 0.90 \\
\hline $\begin{array}{l}\text { DAPSA, mean (SD)/ } \\
\text { median }\left(\mathbf{2 5}^{\text {th }}, \mathbf{7 5}^{\text {th }} \text { percentile) }\right.\end{array}$ & $\begin{array}{l}29.1(17.4) / \\
26.1(18.0,37.5)\end{array}$ & $15.1(13.7) /$ & $12.1(5.1,20.4)$ \\
\hline $\begin{array}{l}\text { DAPSA28, mean }(\text { SD)/ } \\
\text { median }\left(\mathbf{2 5}^{\text {th }}, \mathbf{7 5}^{\text {th }} \text { percentile) }\right.\end{array}$ & $26.9(15.7) /$ & $13.8(12.5) /$ & 0.93 \\
\hline
\end{tabular}

*Standardized mean difference $=$ mean of DAPSA or DAPSA28 in patients starting bDMARD subtracted by the mean of DAPSA or DAPSA28 in patients not starting or changing s/bDMARD) divided by pooled SD of both treatment groups.

Agreements between DAPSA and DAPSA28 disease activity states, ${ }^{4}$ using same cut-offs for DAPSA28 as DAPSA, were best for patients in remission and low disease activity (table 3 ). DAPSA and DAPSA28 disease activity states were in agreement in 5520 of 6421 (86\%) visits, 
had one grade difference in 887 of $6421(13.8 \%)$ visits and two grade difference in 18 (0.2\%) visits.

Table 3 Agreement between DAPSA and DAPSA28 disease activity states

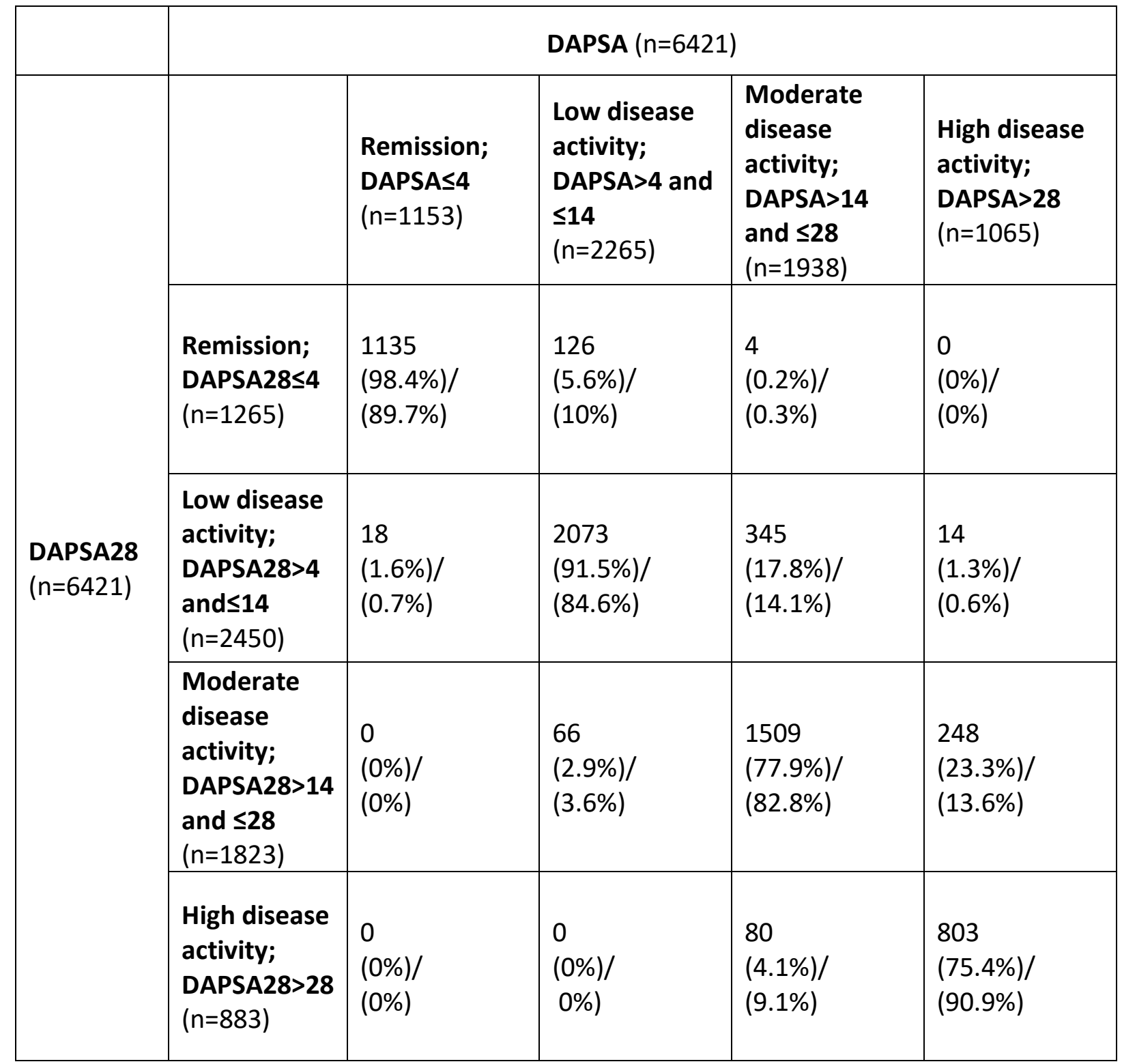

$\mathrm{n}(\%)$ within DAPSA disease activity states/ (\%) within DAPSA28 disease activity states

Kappa with linear/ quadratic weighting between DAPSA/DAPSA28 disease activity states was $0.87,95 \% \mathrm{Cl}(0.86-0.87) / 0.9295 \% \mathrm{Cl}(0.92-0.92)$ indicating very good agreement. However, table 3 indicates that the agreement differed according to disease activity states. Kappa with linear/quadratic weighting between DAPSA/DAPSA28 remission was 0.93 (0.91-0.94)/ 0.93 (0.92-0.94).

SRM for very first follow-up visit after start of bDMARD was -0.79 for DAPSA and -0.74 for DAPSA28 ( $n=232$ ). SRM for first follow-up visit with available SRM value after start of bDMARD was -0.96 for DAPSA and -0.92 for DAPSA28 $(n=572)$. 


\section{Correlational validity}

Correlations were high between differences in 28SJC and 66SJC $(r=0.84, p<0.001(n=5758))$ and between 28TJC and 68TJC $(r=0.85, p<0.001(n=6215))$ from start of $s / b D M A R D$ treatment to follow-up visits.

Scatterplots showed high correlation between DAPSA and DAPSA28 with higher spread for higher disease activity levels and more scores in the upper half (figure 1). Scatterplots of baseline DAPSA vs. DAPSA28 stratified according to DAPSA disease activity states showed high correlation for patients in remission, low and high disease activity and substantial correlation for patients in moderate disease activity (supplementary figure S2a-d).

DAPSA/DAPSA28 had both high correlations with DAS28CRP, SDAI and CDAI at baseline, as well as for all registered visits (table 4).

Table 4 Correlational validity; Pearson correlations at baseline and of all visits

\begin{tabular}{|c|c|c|c|c|c|}
\hline \multicolumn{6}{|c|}{ Baseline/ All visits (grey background) } \\
\hline & DAPSA & DAPSA28 & DAS28CRP & SDAI & CDAI \\
\hline DAPSA & 1 & $\begin{array}{l}0.93^{*} \\
(n=1033)\end{array}$ & $\begin{array}{l}0.87^{*} \\
(n=1033)\end{array}$ & $\begin{array}{l}0.92^{*} \\
(n=947)\end{array}$ & $\begin{array}{l}0.92^{*} \\
(n=947)\end{array}$ \\
\hline DAPSA28 & $\begin{array}{l}0.94^{*} \\
(n=6421)\end{array}$ & 1 & $\begin{array}{l}0.93^{*} \\
(n=2399)\end{array}$ & $\begin{array}{l}0.99 * \\
(n=2148)\end{array}$ & $\begin{array}{l}0.99 * \\
(n=2148)\end{array}$ \\
\hline DAS28CRP & $\begin{array}{l}0.89 * \\
(n=6421)\end{array}$ & $\begin{array}{l}0.94 * \\
(n=20406)\end{array}$ & 1 & $\begin{array}{l}0.94^{*} \\
(n=2189)\end{array}$ & $\begin{array}{l}0.92^{*} \\
(n=2189)\end{array}$ \\
\hline SDAI & $\begin{array}{l}0.94^{*} \\
(n=5888)\end{array}$ & $\begin{array}{l}0.99 * \\
(n=18565)\end{array}$ & $\begin{array}{l}0.94^{*} \\
(n=18819)\end{array}$ & 1 & $\begin{array}{l}0.99 * \\
(n=2189)\end{array}$ \\
\hline CDAI & $\begin{array}{l}0.94^{*} \\
(n=5888)\end{array}$ & $\begin{array}{l}0.99 * \\
(n=18565)\end{array}$ & $\begin{array}{l}0.92^{*} \\
(n=18819)\end{array}$ & $\begin{array}{l}0.99 * \\
(n=18819)\end{array}$ & 1 \\
\hline
\end{tabular}

${ }^{*} p<0.001$ ( $p$ found by GEE when multiple registrations per patient)

Bland Altman plots showed better agreement between DAPSA and DAPSA28 for low than high disease activity levels (figure 2).

The differences between DAPSA and DAPSA28 increased with an increasing average of DAPSA and DAPSA28. ${ }^{11}$ This difference between DAPSA and DAPSA28 was skewed and log transformation (which is the only transformation recommended by Bland and Altman for this plot) did not improve the skewness, hence limits of agreement are not given as they would be invalid. ${ }^{11}$ 


\section{Construct validity}

DAPSA/DAPSA28 were both substantially correlated to HAQ; all visits with DAPSA $(n=6204)$ $r=0.60 / 0.62$; baseline visits with DAPSA $(n=994) r=0.53 / r=0.56$; starting bDMARD $(n=387)$ $r=0.55 / r=0.59$; not starting bDMARD $(n=5817) r=0.59 / r=0.61$, respectively, all $p<0.001$. Mean (SD) HAQ was similar for different DAPSA vs. DAPSA28 categories; remission, $0.2(0.3) /$ 0.2 (0.3); low disease activity $0.6(0.5) / 0.6(0.5)$; moderate disease activity $1.0(0.6) / 1.1$ (0.6); high disease activity, $1.5(0.6) / 1.5(0.6)$, respectively.

Mean (SD) DAPSA and DAPSA28 were comparable for different change and state scores used as external anchors, but mean values of DAPSA were consistently higher than for DAPSA28 (supplementary table $\mathrm{S} 1$ ).

\section{DISCUSSION}

For full assessment of disease activity in PsA there is general agreement about the need to assess a full joint count with 68 tender and 66 swollen joints. However, many databases and registries only collect 28 joint counts. We used the Danish national quality registry DANBIO to explore psychometric performance of a modified DAPSA based on 28 rather than $66 / 68$ joint counts.

DAPSA28 showed overall good criterion, correlational and construct validity as well as sensitivity to change, but the agreement between DAPSA and DAPSA28 was better for low than high disease activity levels. Psychometric performance was also poorer in patients with moderate and high disease activity.

Most patients were classified as having the same disease activity levels, regardless of the use of DAPSA or DAPSA28. When discrepancies occurred, these were moderate in magnitude and more frequent for patients in high disease activity. Kappa with quadratic weighting was high, indicating very good agreement between DAPSA and DAPSA28.

Correlational validity was good, including high correlations between DAPSA/DAPSA28 and DAS28, SDAI and CDAI. All these scores are joint focused and include many of the same variables. DAS28 has been validated for use in PsA in clinical trials of biologic therapies and SDAI in an observational study on PsA patients. ${ }^{12-14}$ Of note, longitudinal observational studies on PSA patients comparing the performance of DAPSA, DAS28, SDAI and CDAI are lacking in the current literature.

The main objection against the use of DAPSA28 in PsA is the 28 joint counts. It is undisputable that a full joint count is preferable to the 28 joint counts in PsA. However, as previously mentioned, in many registries and real life observational studies a full joint count is not available.

Further general objections against DAPSA, as well as DAPSA28, are the need for assessment of multiple domains in PsA. ${ }^{5}$ However, we believe that in addition to the more extensive composite scores of disease activity in PsA like PASDAS ${ }^{15}$ or CPDAI $^{15}$, there may be a need for 
more feasible composite scores like DAPSA/DAPSA28. This issue is under constant debate $e^{4-6}$ 15 and a task force has recently recommended DAPSA for use in PSA. ${ }^{15}$

To our knowledge DAPSA28 is the first 28 joint disease activity score developed and validated in PsA. It is easy to calculate and may pose an important substitute to DAS28, which probably is the mostly used 28-joint composite score in PsA, even if originally developed for RA. ${ }^{16}$ Still, we do not recommend the use of DAPSA28 in clinical practice, as the 66/68 joint counts should be used in PsA whenever feasible. Of note, none of the joint counts distinguishes between the potentially different clinical relevance of which joints being affected.

The psychometric performance of DAPSA28 in patients with moderate and high disease activity was not as good as in patients in remission or with low disease activity. This observation may not be surprising since the distal interphalangeal joints and foot joints may be assumed to be more frequently inflamed in patients with increasingly overall inflammatory activity.

Limitations of the study include non-standardized times of visits (observational database) as well as lack of radiographic data, which could have been useful for additional criterion validation. The results may be influenced by choice of study population, as patients in e.g. low-income countries may have higher disease activity and different cultural background, which possibly might influence the identification of conversion factors. The major strength of the study is the large study population from the national Danish longitudinal observational database DANBIO, including large numbers of patients with 66/68 joint counts and extensive clinical data, as well as patients with both early and established disease.

In conclusion, we recommend that the original DAPSA should be preferred and that 66/68 joint counts should be performed in patients with PsA to compute DAPSA. However, our study suggests that data sets with only 28-joint counts available can be used to calculate a modified DAPSA28, as a valid tool for database or outcomes research in the field of PsA, especially in patients with low disease activity. 
Acknowledgements Thanks to the departments of rheumatology in Aalborg, Aarhus, Esbjerg, Fredericia, Frederiksberg, Gentofte, Glostrup, Gråsten, Hjørring, Holbæk, Holstebro, Horsens, Helsing $\varnothing r$, Kolding, Køge, Næstved/Nykøbing Falster, Odense, Randers, Rigshospitalet, Roskilde, Silkeborg, Slagelse, Svendborg, Vejle, Viborg, Denmark for reporting to the DANBIO registry.

Contributors NSK and MLH were responsible for data acquisition. BM analysed the data and wrote the manuscript. All authors were responsible for study design, critical revision of the manuscript and approval of the final version.

Funding DANBIO is supported by unrestricted grants from AbbVie $A / S$, Biogen (Denmark) A/S, Bristol-Myers Squibb Danmark, Eli Lilly Denmark, MSD Danmark ApS, Novartis Danmark $A / S$, Pfizer Danmark ApS, Roche A/S, UCB Nordic A/S. These entities have no influence on DANBIO's work, including user interface, data collection, statistical analyses or research projects. BM has received clinical research fellowships from Diakonhjemmet Hospital and the Hospital of Southern Norway Trust.

Competing interests TKK has received fees for speaking and/or consulting from AbbVie, Biogen, BMS, Boehringer Ingelheim, Celgene, Celltrion, Eli Lilly, Epirus, Hospira, MerckSerono, MSD, Mundipharma, Novartis, Oktal, Orion Pharma, Hospira/Pfizer, Roche, Sandoz and UCB and received research funding to Diakonhjemmet Hospital from AbbVie, BMS, MSD, Pfizer, Roche and UCB. MLH has received research funding/consultancy/speakers fee from Abbvie, Biogen, BMS, CellTrion, MSD, Novartis, Orion, Pfizer, Samsung, UCB. All other authors have declared that no competing interests exist. 


\section{REFERENCES}

1. Eberl G, Studnicka-Benke A, Hitzelhammer H, et al. Development of a disease activity index for the assessment of reactive arthritis (DAREA). Rheumatology (Oxford) 2000;39:148-55.

2. Schoels M, Aletaha D, Funovits J, et al. Application of the DAREA/DAPSA score for assessment of disease activity in psoriatic arthritis. Ann Rheum Dis 2010;69:1441-7.

3. Nell-Duxneuner VP, Stamm TA, Machold KP, et al. Evaluation of the appropriateness of composite disease activity measures for assessment of psoriatic arthritis. Ann Rheum Dis 2010;69:546-9.

4. Schoels MM, Aletaha D, Alasti $F$, et al. Disease activity in psoriatic arthritis (PsA): defining remission and treatment success using the DAPSA score. Ann Rheum Dis 2016;75:811-8.

5. Helliwell PS, Coates LC. The definition of remission in psoriatic arthritis: can this be accurate without assessment of multiple domains? Ann Rheum Dis 2015;74:e66.

6. Schoels MM, Aletaha D, Smolen JS. Defining remission and treatment success using the DAPSA score: response to letter by Helliwell and Coates. Ann Rheum Dis 2015;74:e67.

7. Fuchs HA, Brooks RH, Callahan LF, et al. A simplified twenty-eight-joint quantitative articular index in rheumatoid arthritis. Arthritis Rheum 1989;32:531-7.

8. Aletaha D, Martinez-Avila J, Kvien TK, et al. Definition of treatment response in rheumatoid arthritis based on the simplified and the clinical disease activity index. Ann Rheum Dis 2012;71:1190-6.

9. Smolen JS, Breedveld FC, Eberl G, et al. Validity and reliability of the twenty-eight-joint count for the assessment of rheumatoid arthritis activity. Arthritis Rheum 1995;38:38-43.

10. Hetland ML. DANBIO--powerful research database and electronic patient record. Rheumatology (Oxford) 2011;50:69-77.

11. Bland JM, Altman DG. Statistical methods for assessing agreement between two methods of clinical measurement. Lancet 1986;1:307-10.

12. Fransen J, Antoni C, Mease PJ, et al. Performance of response criteria for assessing peripheral arthritis in patients with psoriatic arthritis: analysis of data from randomised controlled trials of two tumour necrosis factor inhibitors. Ann Rheum Dis 2006;65:1373-8.

13. Salaffi F, Ciapetti A, Carotti M, et al. Disease activity in psoriatic arthritis: comparison of the discriminative capacity and construct validity of six composite indices in a real world. Biomed Res Int 2014;2014:528105.

14. Saber TP, Ng CT, Renard G, et al. Remission in psoriatic arthritis: is it possible and how can it be predicted? Arthritis Res Ther 2010;12:R94.

15. Smolen JS, Schols M, Braun J, et al. Treating axial spondyloarthritis and peripheral spondyloarthritis, especially psoriatic arthritis, to target: 2017 update of recommendations by an international task force. Ann Rheum Dis 2018;77:3-17.

16. Helliwell PS, Fitzgerald O, Mease PJ. Development of composite measures for psoriatic arthritis: a report from the GRAPPA 2010 annual meeting. J Rheumatol 2012;39:398-403. 

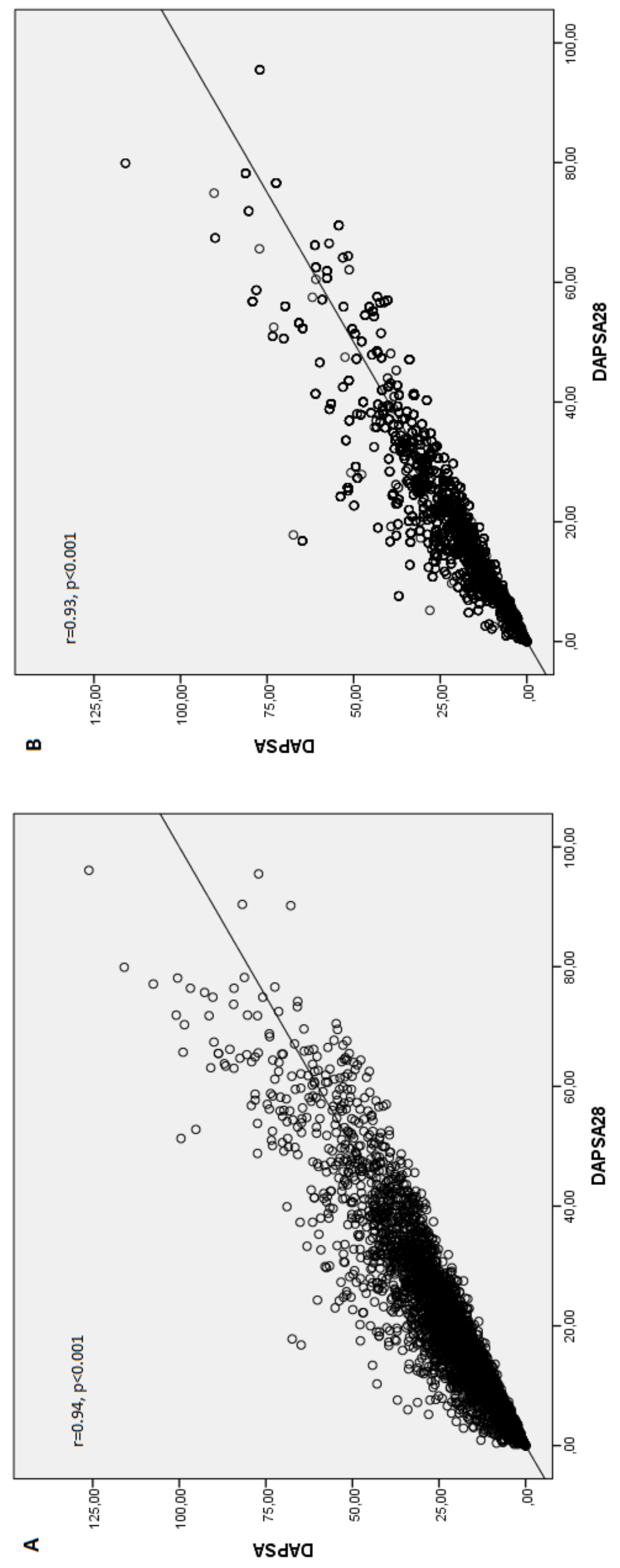

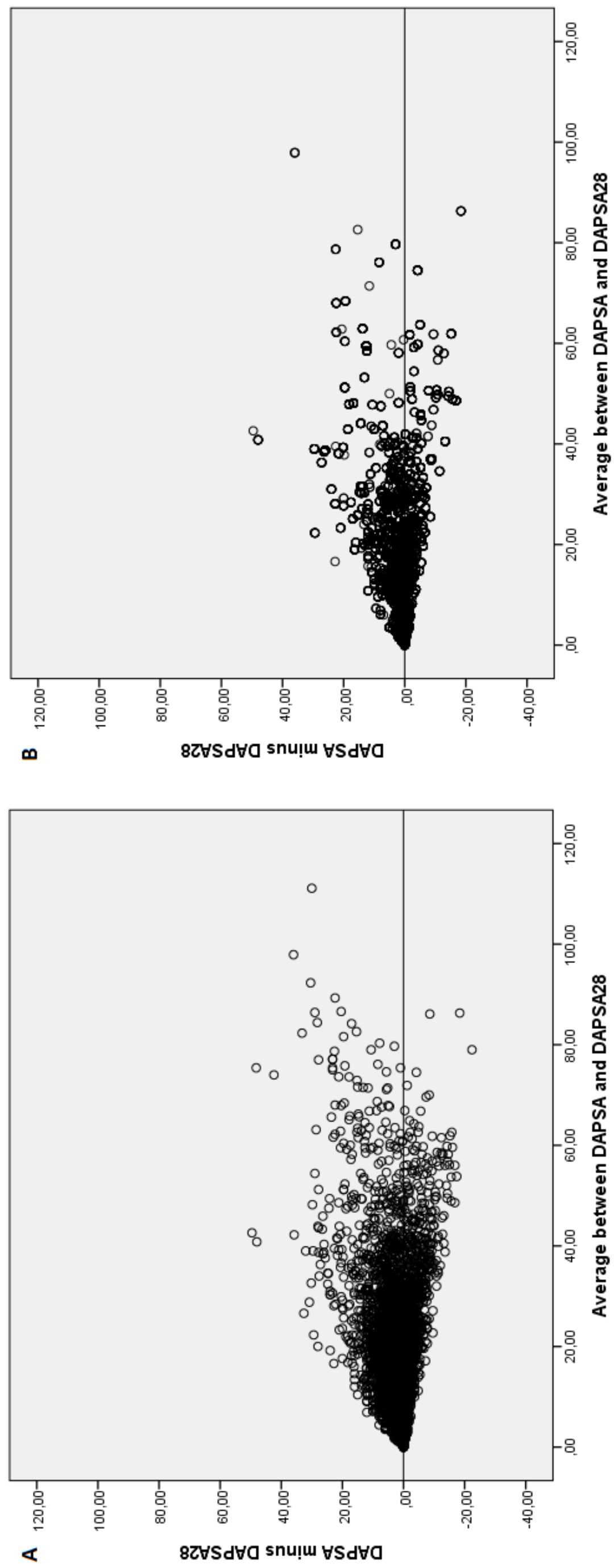
Supplementary figure S1 Boxplot of DAPSA and DAPSA28 (all visits, $n=6421$ )

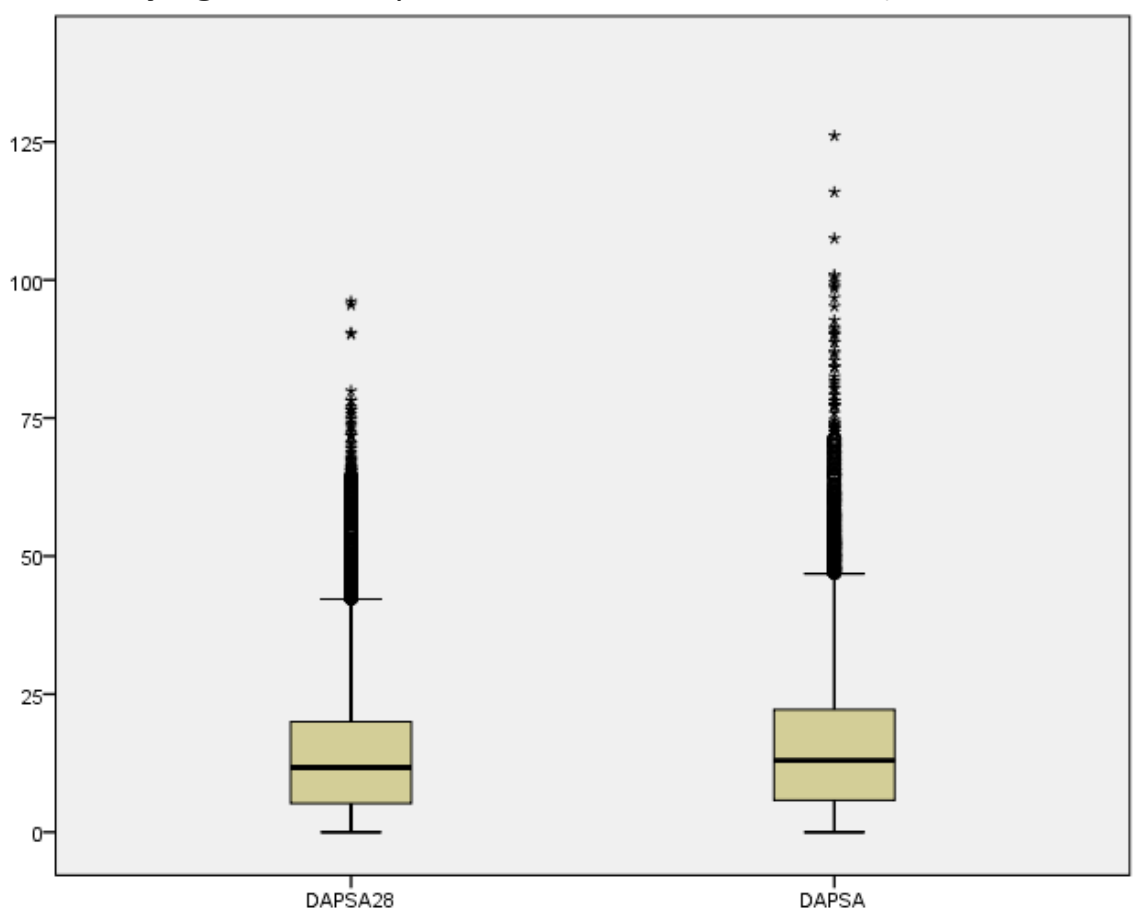


Supplementary Figure S2a Scatterplot of baseline DAPSA and DAPSA28 for patients in DAPSA remission $(n=141)$

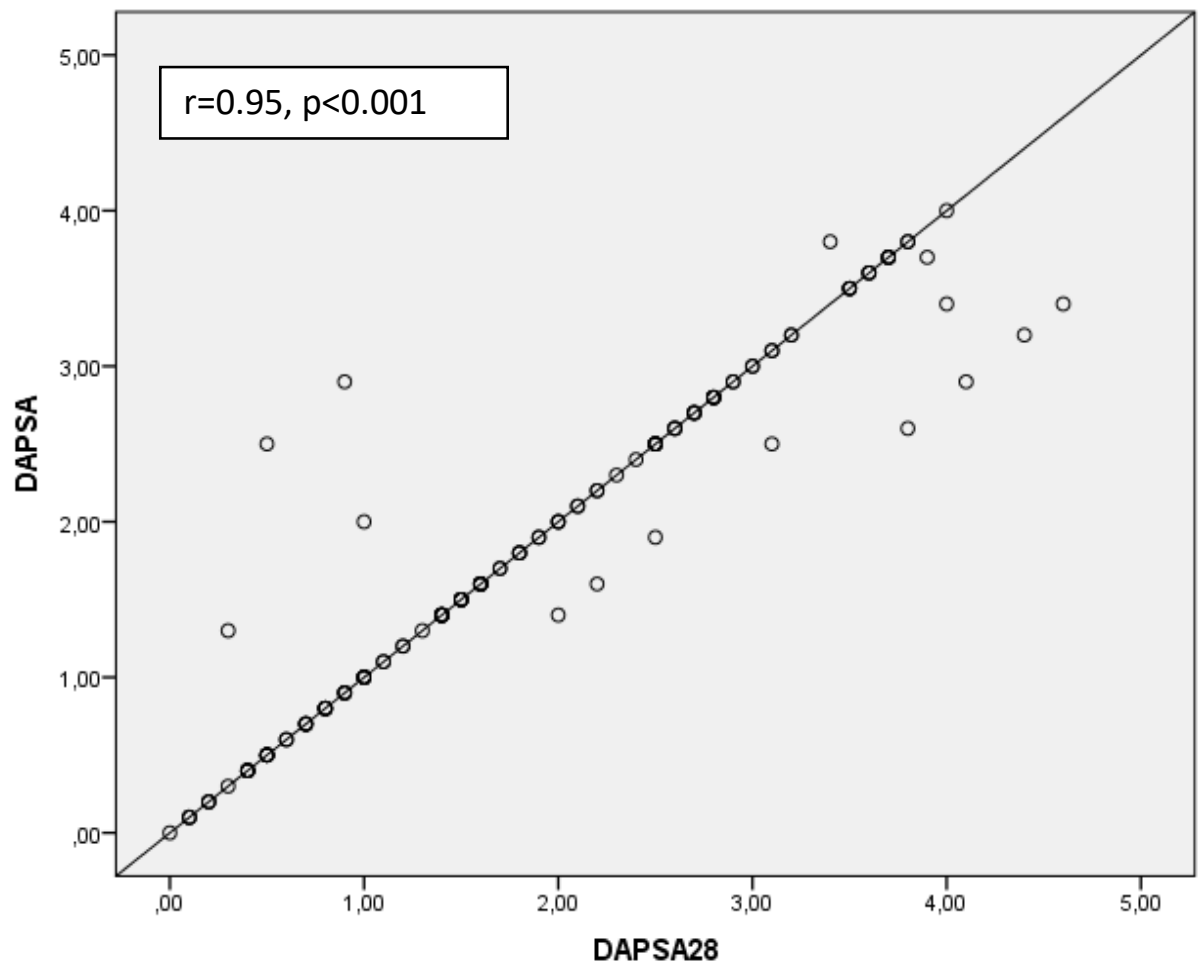

Supplementary Figure S2b Scatterplot of baseline DAPSA and DAPSA28 for patients in DAPSA low disease activity $(n=342)$

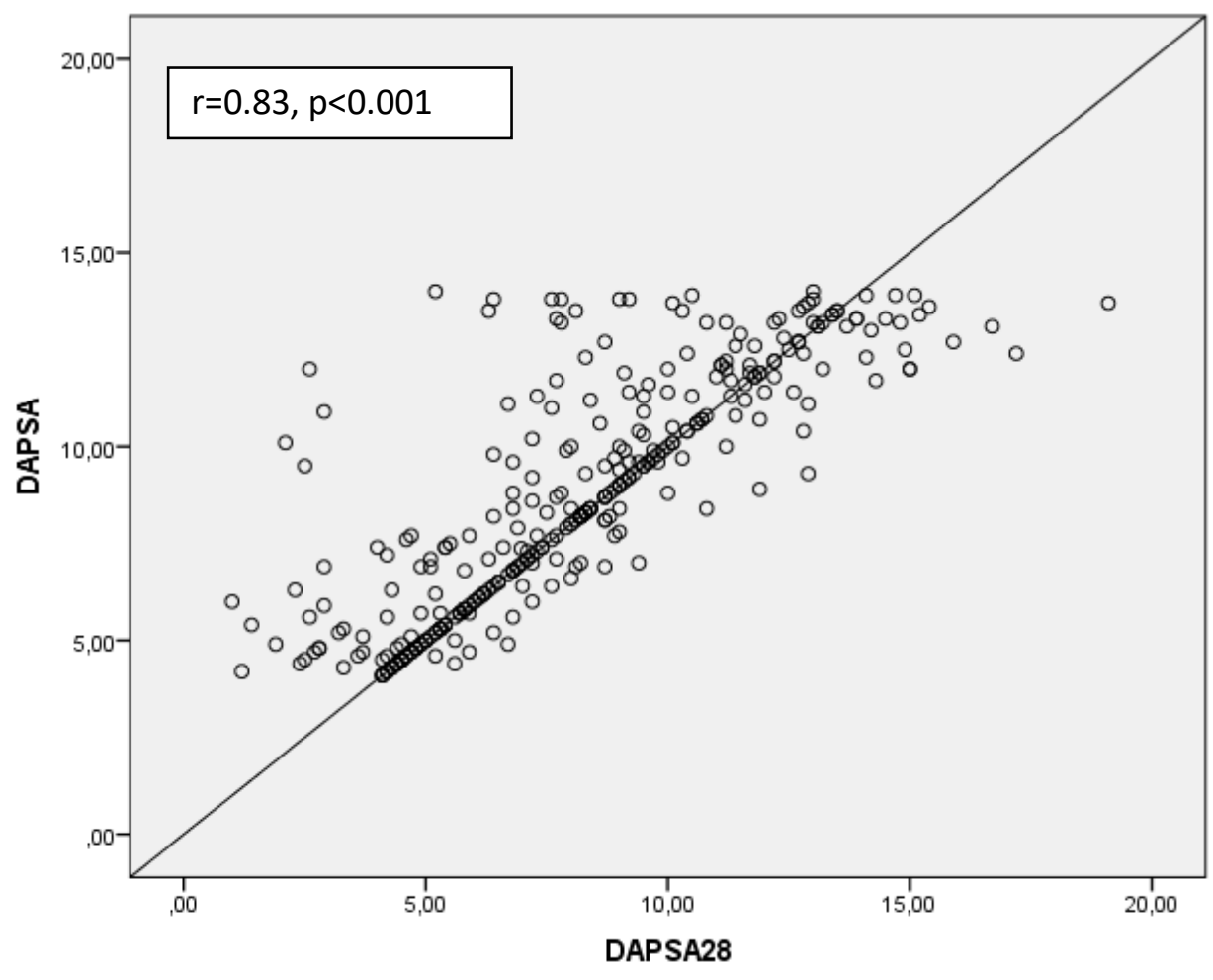


Supplementary Figure S2c Scatterplot of baseline DAPSA and DAPSA28 for patients in DAPSA moderate disease activity $(n=327)$

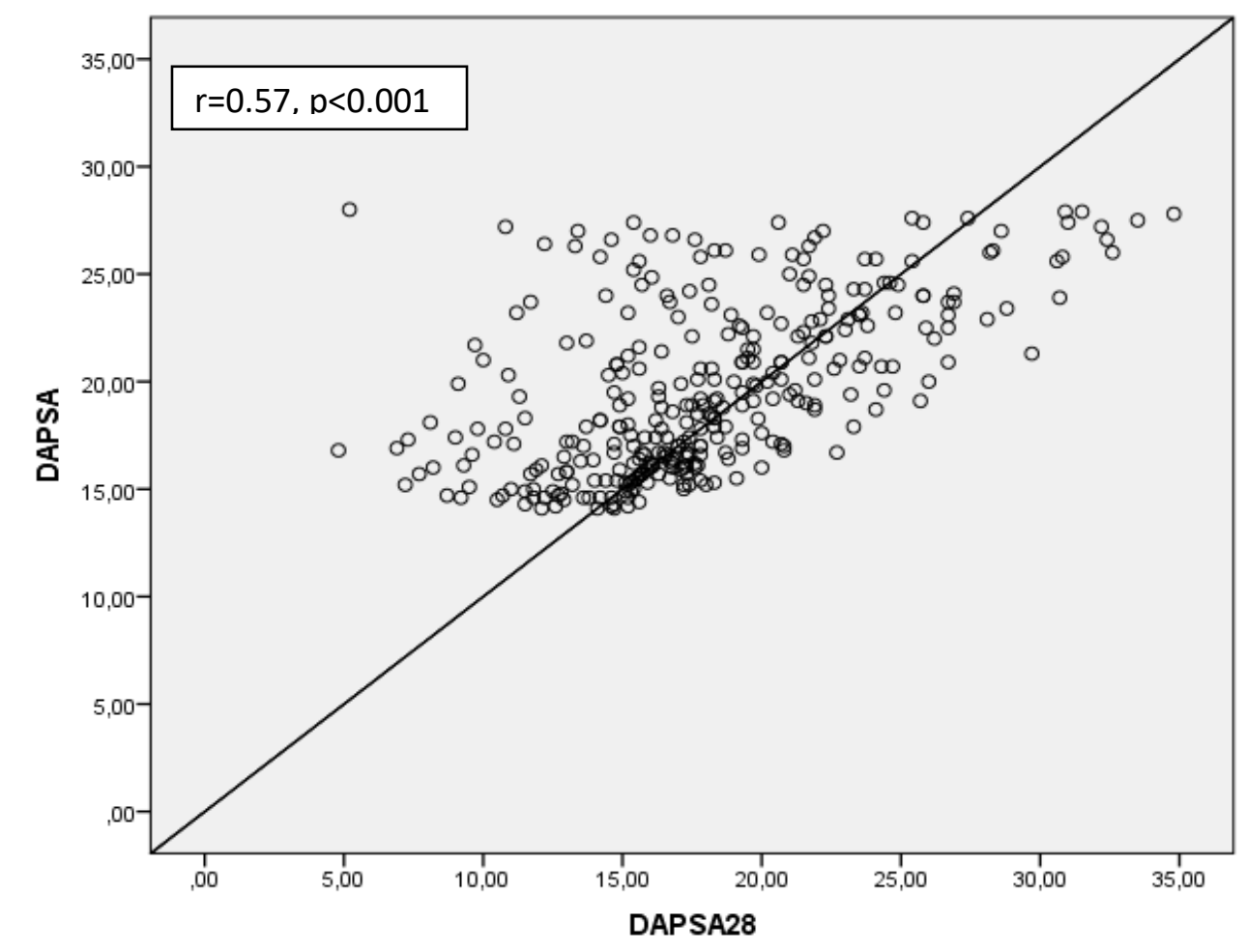

Supplementary Figure S2d Scatterplot of baseline DAPSA and DAPSA28 for patients in DAPSA high disease activity $(n=223)$

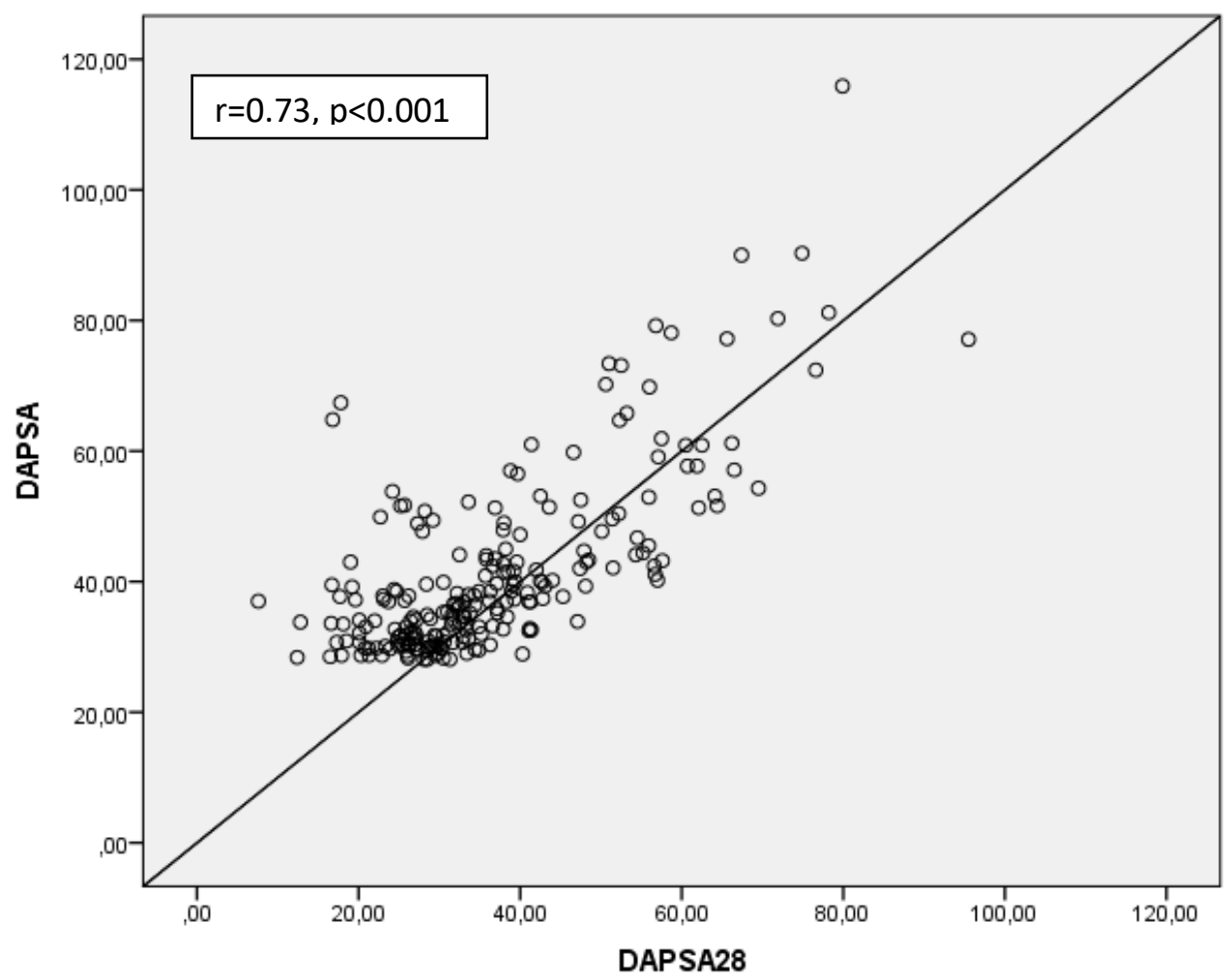


Supplementary table S1 Construct validity, External anchors

\begin{tabular}{|c|c|c|c|}
\hline & & $\begin{array}{l}\text { DAPSA } \\
\text { mean (SD) }\end{array}$ & $\begin{array}{l}\text { DAPSA28 } \\
\text { mean (SD) }\end{array}$ \\
\hline \multirow{7}{*}{$\begin{array}{l}\text { Patient's evaluation } \\
\text { of disease activity } \\
\text { since last visit } \\
(n=1485)\end{array}$} & Much worse (n=71) & $34.0(13.4)$ & $30.3(11.6)$ \\
\hline & Worse $(n=237)$ & $24.1(12.5)$ & $22.7(12.4)$ \\
\hline & Little worse $(n=328)$ & $18.2(15.2)$ & 16.4 (12.9) \\
\hline & Unchanged $(n=566)$ & $12.8(13.2)$ & $12.0(12.3)$ \\
\hline & Little better ( $n=146)$ & $12.6(10.1)$ & $11.7(9.7)$ \\
\hline & Better ( $n=99$ ) & $7.3(6.7)$ & $6.8(6.8)$ \\
\hline & Much better $(n=38)$ & $4.6(5.9)$ & $3.6(4.5)$ \\
\hline \multirow{2}{*}{$\begin{array}{l}\text { Patient's acceptable } \\
\text { symptom state } \\
(n=2185)\end{array}$} & Acceptable $(n=1140)$ & $9.1(8.7)$ & $8.4(8.0)$ \\
\hline & Not acceptable $(n=1045)$ & $24.2(14.9)$ & $22.5(13.8)$ \\
\hline \multirow{2}{*}{$\begin{array}{l}\text { Physician's global } \\
\text { assessment }(n=5888)\end{array}$} & $<10(0-100$ scale) $(n=3184)$ & $9.4(8.3)$ & $8.8(7.9)$ \\
\hline & $\geq 10$ (0-100 scale) $(n=2704)$ & $24.6(16.0)$ & 22.1 (14.9) \\
\hline
\end{tabular}

